\title{
Predictive performance for placental dysfunction related stillbirth of the competing risks model for small for gestational age fetuses
}

\author{
Kypros Nicolaides ${ }^{1}$, Ioannis Papastefanou ${ }^{2}$, Argyro Syngelaki ${ }^{3}$, Ghalia Ashoor ${ }^{4}$, and Ranjit \\ Akolekar 5 \\ ${ }^{1}$ Fetal Medicine Institute \\ ${ }^{2}$ Fetal Medicine Clinic, Monis Petraki 4, Kolonaki, 11521, Athens, Greece \\ ${ }^{3}$ King's College Hospital \\ ${ }^{4}$ Fetal Medicine Research Institute \\ ${ }^{5}$ Medway Maritime Hospital
}

October 27, 2021

\begin{abstract}
Objectives: First, to examine the predictive performance for placental dysfunction related stillbirths of the competing risks model for small for gestational age (SGA) fetuses based on a combination of maternal risk factors, estimated fetal weight (EFW) and uterine artery pulsatility index (UtA-PI); and second, to compare the performance of this model to that of stillbirth-specific model utilizing the same biomarkers and to the Royal College of Obstetricians and Gynecologists (RCOG) guideline for the investigation and management of the SGA fetus. Design: Prospective observational study. Setting: Two UK maternity hospitals. Population: 131,514 women with singleton pregnancies attending for routine ultrasound examination at 19-24 weeks' gestation. Methods: The predictive performance for stillbirth achieved by three models was compared. Main outcome measures: Placental dysfunction related stillbirth. Results: At $10 \%$ false positive rate, the competing risks model predicted $59 \%, 66 \%$ and $71 \%$ of placental dysfunction related stillbirths, at any gestation, at $<37$ weeks and at $<32$ weeks, respectively, which were similar to the respective figures of $62 \%, 70 \%$ and $73 \%$ for the stillbirth-specific model. At a screen positive rate of $21.8 \%$, as defined by the RCOG guideline, the new model predicted $71 \%, 76 \%$ and $79 \%$ of placental dysfunction related stillbirths at any gestation, at $<37$ weeks and at $<32$ weeks, respectively, and the respective figures for the RCOG guideline were $42 \%, 44 \%$ and $40 \%$. Conclusion: The predictive performance for placental dysfunction related stillbirths by the competing risks model for SGA was similar to the stillbirth-specific model and superior to the RCOG guideline.
\end{abstract}

\section{INTRODUCTION}

Development of preventive strategies for stillbirth necessitate recognition that first, the aetiology is heterogeneous and often unknown, and second, the majority of stillbirths are related to placental dysfunction, reflected in the coexistence of small for gestational age (SGA) fetuses and / or preeclampsia. In a prospective study on screening for adverse obstetric outcomes involving 131,514 women with singleton pregnancies attending for routine pregnancy care at 19-24 weeks' gestation, there were $477(0.36 \%)$ stillbirths, $92.5 \%$ of which were antepartum and $7.5 \%$ intrapartum; placental dysfunction related stillbirths accounted for $59 \%$ of all antepartum stillbirths ${ }^{1}$. The dataset was used to develop and validate a logistic regression model for prediction of placental dysfunction related stillbirth; a combination of maternal risk factors, sonographic estimated fetal weight (EFW) and uterine artery pulsatility index (UtA-PI) predicted, at $10 \%$ false positive rate (FPR), $62 \%$ of all cases of placental dysfunction related stillbirths, $70 \%$ of those at $<37$ weeks' gestation and $29 \%$ of those at [?]37 weeks.

In $93 \%$ of the placental dysfunction related stillbirths the birth weight was below the $10^{\text {th }}$ percentile of 
The Fetal Medicine Foundation population charts $^{1,2}$. It may therefore be preferable to use one model for prediction of both SGA and stillbirth, rather than two separate models; the management of pregnancies at high risk for these conditions is essentially the same and involves serial ultrasound examinations for early diagnosis of SGA and then Doppler assessment of the fetal circulation to determine the best time and mode of delivery. The traditional approach to identify a high risk group for SGA is the application of a scoring system. For example, in the UK, according to guidelines by the Royal College of Obstetricians and Gynaecologists (RCOG), a scoring system is applied to identify a high risk group for SGA in need of serial ultrasound scans from 26 weeks onwards ${ }^{3}$. An alternative method is provided by our novel two dimensional continuous competing risks model in which SGA is considered as a spectrum disorder whose severity is continuously reflected in both the gestational age at delivery $(\mathrm{GA})$ and $\mathrm{Z}$ score in birth weight for gestational age $(\mathrm{Z})^{4-8}$. The building block of this model is a patient-specific joint distribution of $\mathrm{Z}$ and GA, that is obtained by combining a history model with multivariate likelihood of biomarkers according to Bayes theorem ${ }^{4-8}$. Risk computation is feasible for any chosen cut-off in GA and Z, at any stage of pregnancy by adding any desired biomarker in the same model.

The objective of this study was to examine the predictive performance for placental dysfunction related stillbirths by the competing risks model for SGA based on a combination of maternal risk factors, EFW and UtA-PI and compare the performance to that of our stillbirth-specific logistic regression model using the same biomarkers ${ }^{1}$ and to the RCOG guideline for the investigation and management of the SGA fetus ${ }^{3}$.

\section{METHODS}

\section{Study population and design}

The data for this study were derived from prospective screening for adverse obstetric outcomes in women attending for routine pregnancy care at $19^{+0}-24^{+6}$ weeks' gestation at King's College Hospital and Medway Maritime Hospital, UK, between 2011 and 2020. In this visit we first, recorded maternal demographic characteristics and medical history as self-reported by the patients, second, carried out an ultrasound examination for fetal anatomy and measurement of fetal head circumference, abdominal circumference and femur length to calculate the EFW by the Hadlock formula ${ }^{9}$, because a systematic review identified this as being the most accurate model ${ }^{10}$, and third, measured the left and right UtA-PI either by transvaginal or transabdominal color Doppler ultrasound and calculated the mean value of the two arteries ${ }^{11,12}$. The majority of UtA-PI measurements were carried out transvaginally because at the same time we were measuring cervical length; the transabdominal approach was used when women declined transvaginal sonography. Gestational age was determined from measurement of fetal crown-rump length at 11-13 weeks or the fetal head circumference at 19-24 weeks ${ }^{13,14}$. The same study population was used for development and validation of the model based on multivariable logistic regression analysis for prediction of placental dysfunction related stillbirth ${ }^{1}$.

The inclusion criteria for this study were singleton pregnancies that delivered a phenotypically normal live birth or stillbirth at $>24$ weeks' gestation. We excluded pregnancies with known aneuploidies, major fetal abnormalities, those ending in a miscarriage or termination of pregnancy. There was no patient involvement in the design of the study.

\section{Study funding}

This study was supported by grants from the Fetal Medicine Foundation (UK Charity No: 1037116). This body had no involvement in the study design; in the collection, analysis and interpretation of data; in the writing of the report; and in the decision to submit the article for publication.

\section{Outcome measures}

Data on pregnancy outcome were obtained from the maternity hospital records or the general practitioners of women. Stillbirths were divided into those that occurred prenatally and those that occurred during labour (intrapartum stillbirths). Antepartum stillbirths were divided into those that were associated with placental dysfunction (preeclampsia or birthweight $<10^{\text {th }}$ percentile) and those due to other causes. Antepartum stillbirths were further divided based on gestational age at stillbirth into those that occurred at any gestational 
age, at $<37$ weeks and at $<32$ weeks.

\section{Statistical analyses}

Data from continuous variables were expressed as medians and interquartile ranges and from categorical data as n (\%). Comparison of the maternal characteristics between the outcome groups was by the $\chi^{2-}$ square test or Fisher's exact test for categorical variables or Mann-Whitney U-test for continuous variables, respectively. The observed measurements of UtA-PI were expressed as a multiple of the normal median (MoM) after adjustment for maternal and pregnancy characteristics as previously described ${ }^{15}$. The values of EFW were expressed as Z-scores using The Fetal Medicine Foundation population charts ${ }^{2}$. We used Bayes' theorem to combine the prior joint distribution of Z and GA according to the history model with the likelihoods of EFW Z score and UtA-PI MoM to obtain a pregnancy specific posterior distribution; this was used to produce patient specific risks according to the competing risks model for SGA. The distributions of patient-specific risks were used to estimate detection rates (DR) and FPR from analysis of receiver operating characteristic (ROC) curves. Similarly, patient-specific risks were estimated using our previously reported logistic regression model for placental dysfunction related stillbirth ${ }^{1}$. The predictive performance for stillbirth of the competing risks model for $\mathrm{SGA}^{7}$ and the stillbirth-specific logistic regression model for placental dysfunction ${ }^{1}$ was compared. McNemar's test was used to compare detection rates of stillbirth achieved from the application of the RCOG guideline and those resulting from the competing risks model for SGA, at the same screen positive rate as that determined from the use of the RCOG guideline.

The statistical software package $\mathrm{R}$ was used for data analyses. ${ }^{16}$

\section{RESULTS}

\section{Study population}

The entry criteria were fulfilled by 131,514 singleton pregnancies; there were 131,037 livebirths and 477 $(0.36 \%)$ stillbirths, including $441(0.34 \%)$ antepartum and $36(0.03 \%)$ intrapartum stillbirths. The maternal and pregnancy characteristics in stillbirths and livebirths in the study population are summarised in Table 1.

The gestational age distribution of antepartum stillbirths was $<32$ weeks in $45.6 \%(201 / 441)$ of cases, $<37$ weeks in $67.3 \%(297 / 441)$ of cases and at [?]37 weeks in $32.7 \%(144 / 441)$ of cases. The gestational age and birthweight distribution of the antepartum stillbirths is shown in Figure 1. The birthweight was $<10$ th percentile in $55.1 \%(243 / 441)$ of all antepartum stillbirths, including $78.6 \%(158 / 201)$ of those at $<32$ weeks' gestation, $69.4 \%(206 / 297)$ at $<37$ weeks, and $25.7 \%(37 / 144)$ at [?]37 weeks. The birthweight was $<10$ th percentile in $93.1 \%(243 / 261)$ of all placental dysfunction related stillbirths, including $98.1 \%(158 / 161)$ of those at $<32$ weeks' gestation, $96.7 \%(206 / 213)$ at $<37$ weeks, and $78.7 \%(37 / 47)$ at [?]37 weeks.

\section{Comparison of the competing risks model for SGA with the stillbirth-specific logistic regression} model

Prediction of stillbirth, expressed as AUROC and detection rate at $10 \% \mathrm{FPR}$, in screening by maternal risk factors and combinations with EFW and UtA-PI for all stillbirths and the subgroups of antepartum stillbirths and those that were related to placental dysfunction by the two models of screening are summarised in Table 2. At $10 \%$ FPR, the competing risks model predicted $58.6 \%$ (52.6 - 64.6), $66.2 \%$ (59.9 - 72.6), $70.8 \%$ (63.8 77.8) of placental dysfunction related stillbirths, at any gestation, at $<37$ weeks' gestation and $<32$ weeks, respectively, which were similar to the respective figures of $62.3 \%$ (57.2-67.4), $69.8 \%$ (65.0-74.6), and $72.5 \%$ (67.8-77.2) achieved by the application of the stillbirth-specific logistic regression model.

The ROC curves for prediction of all antepartum stillbirths and placental dysfunction related stillbirths, at any gestation, at $<37$ weeks' gestation and at $<32$ weeks, by the competing risks model for SGA fetuses, are shown in Figure 2. The detection rates at 1\%,3\%,5\% and 10\% FPR in screening by the competing risks model utilising maternal risk factors and combinations with EFW and UtA-PI are shown in Table S1. 
Reducing the FPR from $10 \%$ to $3 \%$ results in a relatively mild reduction in the detection rate, an observation that might be useful in balancing effective prediction and availability of resources.

Comparison of the competing risks model for SGA with the RCOG guideline for the prediction of SGA

The variables used for the comparison are given in Table S2. The ROC curves for the prediction of stillbirth by the competing risks model combining maternal risk factors, EFW, and UtA-PI are presented in Figure 2. Prediction of stillbirth by the competing risks model was superior to that of the RCOG guideline (Table 3, Figure 2). At a screen positive rate of $21.8 \%$, as defined by the RCOG guideline, the new model predicted $79 \%, 76 \%$ and $71 \%$ of placental dysfunction related stillbirths at $<32$ weeks' gestation, $<37$ weeks and any gestational age and the respective figures for the RCOG guideline were $42 \%, 44 \%$ and $40 \%^{3}$.

\section{DISCUSSION}

\section{Main findings}

There are three main findings of this large prospective screening study for adverse pregnancy outcome. First, about $60 \%$ of antepartum stillbirths are related to placental dysfunction and in more $90 \%$ of such cases the fetuses are SGA. Second, in screening for placental dysfunction related stillbirth by a combination of maternal risk factors, EFW and UtA-PI utilising the competing risks model for $\mathrm{SGA}^{7}$, the predictive performance is similar to that achieved in screening by a specific logistic regression model for placental dysfunction related stillbirth $^{1}$. Third, the performance of screening by the competing risks model for SGA is by far superior to the RCOG guideline for the investigation and management of the SGA fetus ${ }^{3}$.

\section{Strengths and limitations}

The strengths of the study are: first, large sample size with prospectively collected data, second, focus on placental dysfunction related stillbirths, rather that treating all stillbirths as a homogeneous condition, and third, comparison of the predictive performance of two of our models that were previously internally validated $^{1,7}$. We acknowledge the prerequisite for external validation to support generalization of our results and wide implementation of our model. Such external validation would require a large prospective multicenter study.

It is possible that in some cases the birthweight of the stillborn babies is lower than the weight at the time of death because there is a relationship between intrauterine retention interval and reduction in birthweight ${ }^{34}$. In our cases we did not have information on this interval and therefore the incidence of placental dysfunction related stillbirths maybe overestimated.

A Some of the risk factors included in the RCOG guideline for the prediction of SGA were not included in the competing risks model for SGA because we did not have such risk factors for any or some of our patients. For example, we did not have data on low fruit intake before pregnancy, paternal SGA, daily vigorous exercise, heavy bleeding similar to menses, or notching of the uterine artery Doppler waveforms, but these factors may well suffer from subjectivity or information bias. Similarly, we did not have available data on PAPP-A for all of our patients and did not use the criterion of $<0.4 \mathrm{MoM}$ for assessment of risk; in a previous study we reported that inclusion of PAPP-A as a binary variable $(<0.4 \mathrm{MoMs})$ increases the screen positive rate without any significant improvement in the detection rate. ${ }^{33}$

\section{Comparison with results of previous studies}

In a series of previous first and second trimester studies for the prediction of stillbirth we highlighted that the causes of this adverse event are heterogeneous and that the focus of research should be placental dysfunction related stillbirths because they are relatively common and to a great extent potentially preventable ${ }^{17-22}$. However, a systematic review of 69 previous systematic reviews which aimed to identify variables that could be relevant to the development of a clinical prediction model for stillbirth treated this adverse event as a homogeneous condition. ${ }^{23}$ The study reported that no marker had useful screening performance, but 
maternal age, body mass index and history of prior adverse pregnancy outcomes had a more convincing association than the best performing tests, which were pregnancy-associated plasma protein-A (PAPP-A), placental growth factor (PlGF) and UtA-PI. ${ }^{23}$ Such types of publications that do not recognize the fact that the causes of stillbirth are heterogeneous could not possibly advance the development of strategies for prediction and prevention of stillbirth.

The same group of authors attempted to externally validate previously published prediction models for stillbirth using individual participant data (IPD) meta-analysis from a heterogeneous group of 19 datasets $^{24}$. A literature search identified 40 stillbirth models, but they could only validate three of these models due to lack of availability of the necessary predictors in their dataset or the model equations in the previous publications; surprisingly for such a study there was no attempt to contact the authors of the models to request details on the equations. The authors reported that the three models showed poor and uncertain predictive performance in their data, they had limited clinical utility and that further research is needed to identify stronger prognostic factors and develop more robust prediction models ${ }^{33}$. However, these conclusions are misleading and can have a potential adverse impact on clinical practice and future research, because first, two of the three models they evaluated were based on maternal risk factors only and they overlooked many prediction models based on a combination of maternal risk factors and first or second trimester biomarkers, second, the heterogeneous datasets used for their IPD meta-analysis were not derived from prospective screening for stillbirth and were therefore inadequate for assessing models derived from prospective examination of patients, and third, the authors examined the value of the reported models for prediction of all stillbirths and overlooked the fact that the original publications highlighted that the models provided good prediction of placental dysfunction related stillbirth, particularly those occurring preterm, rather than prediction of all stillbirths.

In our study we have focussed on placental dysfunction related stillbirth, prospectively recorded data from the maternal history and biomarkers shown over the last few decades to be associated with the birth of SGA neonates, developed and validated a model for prediction of SGA and demonstrated that such model can effectively predict a high proportion of stillbirths, especially those that occur preterm. We have previously reported the increased risk for SGA fetuses / neonates is provided by lower maternal weight and height, black, South and East Asian racial origin, medical history of chronic hypertension, diabetes mellitus and systemic lupus erythematosus or antiphospholipid syndrome, conception by in vitro fertilization or ovulation induction and smoking. ${ }^{4}$ For parous women variables from the last pregnancy that increased the risk for SGA were history of preeclampsia or stillbirth, decreasing birth weight z-score and decreasing gestational age at delivery of the last pregnancy and inter-pregnancy interval $<0.5$ years. ${ }^{4}$

\section{Clinical implications of the study}

A high proportion of placental dysfunction related stillbirths can potentially be prevented by a three stage strategy. First, screening for preeclampsia at 11-13 weeks' gestation and treatment of the high-risk group by aspirin; this is effective in the prevention of preterm preeclampsia but also in the prevention of early SGA in the absence of preeclampsia ${ }^{25-30}$. Second, screening during the routine mid-trimester scan by a combination of maternal risk factors, EFW and UtA-PI, which identifies a high-risk group that contains a high proportion of placental dysfunction related stillbirths that occur at 24-37 weeks' gestation; close monitoring of these pregnancies for early diagnosis of SGA fetuses could prevent at least some of such stillbirths by defining the best approach to monitoring and best timing of delivery. The detection rate of stillbirths is higher when UtA-PI is included in the model in addition to maternal risk factors and EFW, highlighting the necessity of including this measurement in the routine mid-trimester scan; it is easy for competent sonographers to learn this technique and it only adds about 2 minutes to the examination. Third, routine ultrasound examination at 36 weeks' gestation, because screening at mid-gestation provides poor prediction of stillbirth at term; more effective screening for late SGA can be achieved by screening at $36^{31,32}$.

\section{Conclusion}

Placental dysfunction related stillbirth is to a great extent predictable and potentially preventable. In more 
than $90 \%$ of such stillbirths the fetuses are SGA and many of these can be predicted at a routine midpregnancy assessment utilising a combination of maternal risk factors ultrasonographic EFW and UtA-PI.

\section{Disclosure of interests}

The authors report no conflict of interest.

\section{Contribution to authorship}

KHN and IP conceptualized and designed the study. AS searched the databases and provided the necessary files for analysis. KHN and RA oversaw the study. IP conducted the statistical analysis. KHN, IP and GA wrote the paper. All authors revised and contributed to the intellectual content of the manuscript.

\section{Details of ethical approval}

Women gave written informed consent to take part in the study which was carried out in compliance with the 1975 Declaration of Helsinki Guidelines. The study was approved by the NHS Research Ethics Committee (REC reference 02-03-033, date of approval 11/03/2003).

\section{REFERENCES}

Ashoor G, Syngelaki A, Papastefanou I, Nicolaides KH, Akolekar R. Development and validation of a model for prediction of placental dysfunction related stillbirth from maternal factors, fetal weight and uterine artery Doppler at mid-gestation. Ultrasound Obstet Gynecol 2021, Oct 13. doi: 10.1002/uog.24795.

1. Nicolaides KH, Wright D, Syngelaki A, Wright A, Akolekar R. Fetal Medicine Foundation fetal and neonatal population weight charts. Ultrasound Obstet Gynecol 2018;52:44-51.

2. Royal College of Obstetricians and Gynaecologists. The Investigation and Management of the Smallfor-Gestational-Age Fetus. Green-top guideline No. 31. RCOG January 2014.

3. Papastefanou I, Wright D, Nicolaides KH. Competing risks model for prediction of small for gestational age neonates from maternal characteristics and medical history. Ultrasound Obstet Gynecol2020;56:196205.

4. Papastefanou I, Wright D, Syngelaki A, Souretis K, Chrysanthopoulou E, Nicolaides KH. Competingrisks model for prediction of small-for-gestational-age neonates from biophysical and biochemical markers at 11-13 weeks' gestation. Ultrasound Obstet Gynecol2021;57:52-61.

5. Papastefanou I, Nowacka U, Syngelaki A, Dragoi V, Karamanis G, Wright D, Nicolaides KH. Competing risks model for prediction of small for gestational age neonates from estimated fetal weight at 19-24 weeks' gestation. Ultrasound Obstet Gynecol 2021. doi: 10.1002/uog.23593.

6. Papastefanou I, Nowacka U, Syngelaki A, Mansukhani T, Karamanis G, Wright D, Nicolaides KH. Competing risks model for prediction of small-for-gestational-age neonates from biophysical markers at 19 to 24 weeks' gestation. Am J Obstet Gynecol 2021. doi: 10.1016/j.ajog.2021.04.247.

7. Papastefanou I, Nowacka U, Buerger O, Akolekar R, Wright D, Nicolaides KH. Evaluation of the RCOG guideline for the prediction of neonates that are small for gestational age and comparison with the competing risks model. BJOG 2021. doi: 10.1111/1471-0528.16815.

8. Hadlock FP, Harrist RB, Sharman RS, Deter RL, Park SK. Estimation of fetal weight with the use of head, body, and femur measurements-a prospective study. Am J Obstet Gynecol . 1985;151:333-37.

9. Hammami A, Mazer Zumaeta A, Syngelaki A, Akolekar R, Nicolaides KH. Ultrasonographic estimation of fetal weight: development of new model and assessment of performance of previous models. Ultrasound Obstet Gynecol 2018;52:35-43.

10. Papageorghiou AT, Yu CKH, Bindra R, Pandis G, Nicolaides KN. Multicentre screening for preeclampsia and fetal growth restriction by transvaginal uterine artery Doppler at 23 weeks of gestation. Ultrasound Obstet Gynecol 2001;18: 441-49.

11. Albaiges G, Missfelder-Lobos H, Lees C, Parra M, Nicolaides KH. One-stage screening for pregnancy complications by color Doppler assessment of the uterine arteries at 23 weeks' gestation. Obstet Gynecol 2000;96:559-64. 
12. Robinson HP, Fleming JE. A critical evaluation of sonar crown rump length measurements. Br J Obstet Gynaecol 1975;82:702-10.

13. Snijders RJ, Nicolaides KH. Fetal biometry at 14-40 weeks' gestation. Ultrasound Obstet Gynecol 1994;4:34-48.

14. Litwinska M, Litwinska E, Lisnere K, Syngelaki A, Wright A, Nicolaides KH. Stratification of pregnancy care based on risk of pre-eclampsia derived from uterine artery Doppler at 19-24 weeks' gestation. Ultrasound Obstet Gynecol 2021 Mar 1. doi: 10.1002/uog.23623. Online ahead of print.

15. R Development Core Team. R: a language and environment for statistical computing: R Foundation for Statistical Computing, Vienna, Austria. Available at:https://www.r-project.org/

16. Smith GC, Yu CK, Papageorghiou AT, Cacho AM, Nicolaides KH, Fetal Medicine Foundation Second Trimester Screening Group. Maternal uterine artery Doppler flow velocimetry and the risk of stillbirth.Obstet Gynecol 2007;109:144-51.

17. Poon LCY, Volpe N, Muto B, Syngelaki A, Nicolaides KH. Birthweight with gestation and maternal characteristics in live births and stillbirths. Fetal Diagn Ther 2012;32:156-65.

18. Yerlikaya G, Akolekar R, McPherson K, Syngelaki A, Nicolaides KH. Prediction of stillbirth from maternal demographic and pregnancy characteristics. Ultrasound Obstet Gynecol 2016;48:607-12.

19. Mastrodima S, Akolekar R, Yerlikaya G, Tzelepis T, Nicolaides KH. Prediction of stillbirth from biochemical and biophysical markers at 11-13 weeks. Ultrasound Obstet Gynecol 2016;48:613-17.

20. Akolekar R, Machuca M, Mendes M, Paschos V, Nicolaides KH. Prediction of stillbirth from placental growth factor at 11-13 weeks. Ultrasound Obstet Gynecol 2016;48:618-23.

21. Akolekar R, Tokunaka M, Ortega N, Syngelaki A, Nicolaides KH. Prediction of stillbirth from maternal factors, fetal biometry and uterine artery Doppler at 19-24 weeks. Ultrasound Obstet Gynecol 2016;48:624-30.

22. Townsend R, Sileo FG, Allotey J, Dodds J, Heazell A, Jorgensen L, Kim VB, Magee L, Mol B, Sandall J, Smith GCS, Thilaganathan B, von Dadelszen P, Thangaratinam S, Khalil A. Prediction of stillbirth: an umbrella review of evaluation of prognostic variables. BJOG 2021;128:238-50.

23. Allotey J, Whittle R, Snell KIE, Smuk M, Townsend R, von Dadelszen P, Heazell AEP, Magee L, Smith GCS, Sandall J, Thilaganathan B, Zamora J, Riley RD, Khalil A, Thangaratinam S; IPPIC Collaborative Network. External validation of prognostic models to predict stillbirth using the International Prediction of Pregnancy Complications (IPPIC) Network database: an individual participant data meta-analysis. Ultrasound Obstet Gynecol 2021 Aug 18. doi: 10.1002/uog.23757.

24. Tan MY, Syngelaki A, Poon LC, Rolnik DL, O'Gorman N, Delgado JL, Akolekar R, Konstantinidou L, Tsavdaridou M, Galeva S, Ajdacka U, Molina FS, Persico N, Jani JC, Plasencia W, Greco E, Papaioannou G, Wright A, Wright D, Nicolaides KH. Screening for pre-eclampsia by maternal factors and biomarkers at 11-13 weeks' gestation. Ultrasound Obstet Gynecol 2018;52:186-95.

25. Wright D, Wright A, Nicolaides KH. The competing risk approach for prediction of preeclampsia. $A m$ J Obstet Gynecol2020;223:12-23.e7.

26. Wright D, Tan MY, O'Gorman N, Poon LC, Syngelaki A, Wright A, Nicolaides KH. Predictive performance of the competing risk model in screening for preeclampsia. Am J Obstet Gynecol 2019; 220: 199.e1-199.e13.

27. Rolnik DL, Wright D, Poon LC, O'Gorman N, Syngelaki A, de Paco Matallana C, Akolekar R, Cicero S, Janga D, Singh M, Molina FS, Persico N, Jani JC, Plasencia W, Papaioannou G, Tenenbaum-Gavish K, Meiri H, Gizurarson S, Maclagan K, Nicolaides KH. Aspirin versus placebo in pregnancies at high risk for preterm preeclampsia. N Engl J Med 2017;377:613-22.

28. Roberge S, Bujold E, Nicolaides KH. Aspirin for the prevention of preterm and term preeclampsia: systematic review and metaanalysis. Am J Obstet Gynecol 2018; 218: 287-293.e1.

29. Tan MY, Poon LC, Rolnik DL, Syngelaki A, de Paco Matallana C, Akolekar R, Cicero S, Janga D, Singh M, Molina FS, Persico N, Jani JC, Plasencia W, Greco E, Papaioannou G, Wright D, Nicolaides KH. Prediction and prevention of small-for-gestational-age neonates: evidence from SPREE and ASPRE. Ultrasound Obstet Gynecol2018;52:52-59.

30. Fadigas C, Saiid Y, Gonzalez R, Poon LC, Nicolaides KH. Prediction of small for gestational age 
neonates: Screening by fetal biometry at 35-37 weeks. Ultrasound Obstet Gynecol 2015;45:559-65.

31. Ciobanu A, Rouvali A, Syngelaki A, Akolekar R, Nicolaides KH. Prediction of small for gestational age neonates: screening by maternal factors, fetal biometry, and biomarkers at 35-37 weeks' gestation. Am J Obstet Gynecol 2019; 220: 486.e1-486.e11.

32. Papastefanou I, Wright D, Syngelaki A, Lolos M, Anampousi K, Nicolaides KH. Competing-risks model for prediction of small-for-gestational-age neonates from maternal characteristics and serum pregnancyassociated plasma protein-A at 11-13 weeks' gestation. Ultrasound Obstet Gynecol 2020;56:541-48.

33. Man J, Hutchinson JC, Ashworth M, Jeffrey I, Heazell AE, Sebire NJ. Organ weights and ratios for postmortem identification of fetal growth restriction: utility and confounding factors. Ultrasound Obstet Gynecol 2016;48:585-90.

\section{FIGURE LEGENTS}

Figure 1. Gestational age distribution of antepartum stillbirths (white histograms) and proportion with birthweight $<10^{\text {th }}$ percentile (black histograms).

Figure 2. Detection rates and screen positive rates by the competing risks model for SGA combining maternal risk factors, Z score of EFW, and UtA-PI MoM for placental dysfunction related stillbirth at $<32$ weeks' gestation (red curve), $<37$ weeks (blue curve), any gestation (green curve) and all antepartum stillbirths (black curve). The circles demonstrate the respective detection rates according to the RCOG guideline.

Table 1. Maternal and pregnancy characteristics in pregnancies that had a stillbirth, stratified according to sub-groups, compared with pregnancies that had live births.

\begin{tabular}{|c|c|c|c|}
\hline $\begin{array}{l}\text { Maternal } \\
\text { characteristics }\end{array}$ & $\begin{array}{l}\text { Live births } \\
(n=131,037)\end{array}$ & Stillbirths & Stillbirths \\
\hline & & All $(n=477)$ & $\begin{array}{l}\text { Placental } \\
\text { dysfunction }(n=261)\end{array}$ \\
\hline $\begin{array}{l}\text { Age in years, median } \\
\text { (IQR) }\end{array}$ & $31.1(26.7-34.9)$ & $31.0(26.4-35.5)$ & $30.7(26.1-35.7)$ \\
\hline $\begin{array}{l}\text { Weight in } \mathrm{Kg} \text {, median } \\
\text { (IQR) }\end{array}$ & $67.2(59.7-78.1)$ & $72.6(63.2-85.0)$ & $74.6(62.6-85.6)$ \\
\hline $\begin{array}{l}\text { Height in } \mathrm{cm} \text {, median } \\
\text { (IQR) }\end{array}$ & $165(160-169)$ & $165(160-168)$ & $164(160-168)$ \\
\hline \multicolumn{4}{|l|}{ Racial origin } \\
\hline White, n (\%) & $95,575(72.9)$ & $270(56.6)$ & $131(50.2)$ \\
\hline Black, n (\%) & $23,397(17.9)$ & $170(35.6)$ & $107(41.0)$ \\
\hline South Asian, n (\%) & $6,045(4.6)$ & $18(3.8)$ & $13(5.0)$ \\
\hline East Asian, n (\%) & $2,496(1.9)$ & $7(1.5)$ & $5(1.9)$ \\
\hline Mixed, n (\%) & $3,524(2.7)$ & $12(2.5)$ & $5(1.9)$ \\
\hline \multicolumn{4}{|l|}{ Method of conception } \\
\hline Spontaneous, n (\%) & $126,500(96.5)$ & $457(95.8)$ & $150(96.6)$ \\
\hline $\begin{array}{l}\text { Assisted conception, } \mathrm{n} \\
(\%)\end{array}$ & $4,537(3.5)$ & $20(4.2)$ & $9(3.5)$ \\
\hline $\begin{array}{l}\text { Cigarette smoking, } \mathrm{n} \\
(\%)\end{array}$ & $12,178(9.3)$ & $64(13.4)$ & $32(12.3)$ \\
\hline $\begin{array}{l}\text { Chronic hypertension, } \\
\mathrm{n}(\%)\end{array}$ & $1,650(1.3)$ & $21(4.4)$ & $18(6.9)$ \\
\hline SLE / APS, n (\%) & $281(0.2)$ & $2(0.4)$ & $2(0.8)$ \\
\hline $\begin{array}{l}\text { Diabetes mellitus, } \mathrm{n} \\
(\%) \\
\text { Parity }\end{array}$ & $1,362(1.0)$ & $13(2.7)$ & $7(2.7)$ \\
\hline
\end{tabular}




\begin{tabular}{|c|c|c|c|}
\hline $\begin{array}{l}\text { Maternal } \\
\text { characteristics }\end{array}$ & $\begin{array}{l}\text { Live births } \\
(\mathrm{n}=131,037)\end{array}$ & Stillbirths & Stillbirths \\
\hline Nulliparous, n (\%) & $62,084(47.4)$ & $236(49.5)$ & $128(49.0)$ \\
\hline $\begin{array}{l}\text { Previous stillbirth, } \mathrm{n} \\
\text { (\%) }\end{array}$ & $975(0.7)$ & $21(4.4)$ & $16(6.1)$ \\
\hline Previous SGA, n (\%) & $9,573(7.3)$ & $57(12.0)$ & $37(14.2)$ \\
\hline $\begin{array}{l}\text { Previous preeclampsia, } \\
\mathrm{n}(\%)\end{array}$ & $3713(2.8)$ & $41(8.6)$ & $30(11.5)$ \\
\hline $\begin{array}{l}\text { Inter-pregnancy } \\
\text { interval in years, } \\
\text { median }(\mathrm{IQR})^{\mathrm{a}}\end{array}$ & $2.9(1.8-4.8)$ & $3.6(2.1-6.6)$ & $4.2(2.4-7.3)$ \\
\hline
\end{tabular}

IQR, interquartile range; SLE, systemic lupus erythematosus; APS, anti-phospholipid syndrome; SGA, small for gestational age; ${ }^{\text {a }}$ Inter-pregnancy interval reported for parous women.

Table 2. Prediction of stillbirth by the two models of screening, expressed as AUROC and detection rate at $10 \%$ false positive rate, in screening by maternal risk factors and combinations with EFW and UtA-PI for all stillbirths and the subgroups of antepartum stillbirths and those that were related to placental dysfunction.

\begin{tabular}{|c|c|c|c|c|}
\hline Outcome measure & $\mathbf{n}$ & Method of screening & Competing risk model for SGA & Competing ris \\
\hline & & & AUROC & DR for FPR 1 \\
\hline \multirow[t]{4}{*}{ All stillbirths } & \multirow[t]{4}{*}{477} & MF & $0.639(0.596-0.682)$ & $23.5(19.7-27.3)$ \\
\hline & & $\mathrm{MF}+\mathrm{EFW}$ & $0.659(0.617-0.702)$ & $34.2(29.9-38.5)$ \\
\hline & & $\mathrm{MF}+\mathrm{UtA}-\mathrm{PI}$ & $0.707(0.667-0.748)$ & $40.7(36.3-45.1)$ \\
\hline & & $\mathrm{MF}+\mathrm{EFW}+\mathrm{UtA}-\mathrm{PI}$ & $0.698(0.657-0.739)$ & $39.4(35.0-43.8)$ \\
\hline \multirow[t]{4}{*}{ Antepartum stillbirths } & \multirow[t]{4}{*}{441} & $\mathrm{MF}$ & $0.643(0.598-0.688)$ & $23.4(19.5-27.4)$ \\
\hline & & $\mathrm{MF}+\mathrm{EFW}$ & $0.670(0.626-0.714)$ & $35.6(31.1-40.1)$ \\
\hline & & $\mathrm{MF}+\mathrm{UtA}-\mathrm{PI}$ & $0.712(0.670-0.754)$ & $42.0(37.4-46.6)$ \\
\hline & & $\mathrm{MF}+\mathrm{EFW}+\mathrm{UtA}-\mathrm{PI}$ & $0.708(0.665-0.750)$ & $41.5(36.9-46.1)$ \\
\hline \multirow[t]{4}{*}{ Placental dysfunction all } & \multirow[t]{4}{*}{261} & MF & $0.689(0.633-0.745)$ & $28.4(22.9-33.9$ \\
\hline & & $\mathrm{MF}+\mathrm{EFW}$ & $0.779(0.729-0.829)$ & $51.3(45.2-57.4)$ \\
\hline & & $\mathrm{MF}+\mathrm{UtA}-\mathrm{PI}$ & $0.804(0.756-0.852$ & $58.2(52.2-64.2$ \\
\hline & & $\mathrm{MF}+\mathrm{EFW}+\mathrm{UtA}-\mathrm{PI}$ & $0.829(0.783-0.875)$ & $58.6(52.6-64.6)$ \\
\hline \multirow[t]{4}{*}{ Placental dysfunction $<37$ weeks } & \multirow[t]{4}{*}{213} & MF & $0.715(0.654-0.776)$ & $32.4(26.1-38.7)$ \\
\hline & & $\mathrm{MF}+\mathrm{EFW}$ & $0.817(0.765-0.869)$ & $58.2(51.6-64.8$ \\
\hline & & $\mathrm{MF}+\mathrm{UtA}-\mathrm{PI}$ & $0.825(0.774-0.876)$ & $63.4(56.9-69.9)$ \\
\hline & & $\mathrm{MF}+\mathrm{EFW}+\mathrm{UtA}-\mathrm{PI}$ & $0.857(0.810-0.904)$ & $66.2(59.9-72.6$ \\
\hline \multirow[t]{4}{*}{ Placental dysfunction $<32$ weeks } & \multirow[t]{4}{*}{161} & MF & $0.722(0.653-0.791)$ & $33.5(26.2-40.8)$ \\
\hline & & $\mathrm{MF}+\mathrm{EFW}$ & $0.859(0.805-0.913)$ & $64.6(57.2-72.0$ \\
\hline & & $\mathrm{MF}+\mathrm{UtA}-\mathrm{PI}$ & $0.819(0.760-0.879)$ & $68.3(61.1-75.5)$ \\
\hline & & $\mathrm{MF}+\mathrm{EFW}+\mathrm{UtA}-\mathrm{PI}$ & $0.871(0.819-0.923)$ & $70.8(63.8-77.8)$ \\
\hline
\end{tabular}

$\mathrm{MF}=$ maternal risk factors, $\mathrm{EFW}=$ estimated fetal weight, UtA-PI = uterine artery pulsatility index

Table 3. Comparisons of detection rates of stillbirths between the competing risks model for SGA and the RCOG guideline. 


\begin{tabular}{|c|c|c|c|c|}
\hline $\begin{array}{l}\text { Outcome } \\
\text { measure }\end{array}$ & Stillbirths & SPR\% & $\begin{array}{l}\text { Comparison of } \\
\text { detection rates } \mathbf{n} \\
(\%) \text { vs. } \mathbf{n}(\%)\end{array}$ & p-value \\
\hline All stillbirths & 477 & 21.8 & $\begin{array}{l}171(35.9) \text { vs. } 240 \\
(50.3)\end{array}$ & $<0.0001$ \\
\hline $\begin{array}{l}\text { Antepartum } \\
\text { stillbirths }\end{array}$ & 441 & 21.8 & $\begin{array}{l}157(35.6) \text { vs. } 230 \\
(52.2)\end{array}$ & $<0.0001$ \\
\hline \multicolumn{5}{|l|}{$\begin{array}{l}\text { Placental } \\
\text { dysfunction all }\end{array}$} \\
\hline Any gestation & 261 & 21.8 & $\begin{array}{l}104(39.9) \text { vs. } 185 \\
(70.9)\end{array}$ & $<0.0001$ \\
\hline$<37$ weeks & 213 & 21.8 & $\begin{array}{l}93(43.7) \text { vs. } 162 \\
(76.1)\end{array}$ & $<0.0001$ \\
\hline$<32$ weeks & 161 & 21.8 & $\begin{array}{l}68(42.2) \text { vs. } 127 \\
(78.9)\end{array}$ & $<0.0001$ \\
\hline
\end{tabular}

RCOG, Royal College of Obstetricians and Gynaecologists; SGA, small for gestational age; SPR, screen positive rate

Competing risks model uses maternal and pregnancy characteristics and medical history, sonographic estimated fetal weight uterine artery pulsatility index.

The SPR was the one that was derived from the RCOG guideline.

McNemar's test was used to compare detection rates of the competing risks model and that of the RCOG guideline.

\begin{tabular}{|c|c|c|c|c|}
\hline Outcome measure & $\mathbf{n}$ & Method of screening & Detection rate at false positive rates of: & Detect \\
\hline & & & $1 \%$ & $3 \%$ \\
\hline \multirow[t]{4}{*}{ All stillbirths } & 477 & MF & $5.9(3.8-8.0)$ & $12.4(9$ \\
\hline & & $\mathrm{MF}+\mathrm{EFW}$ & $18.5(15.0-22.0)$ & 22.9 \\
\hline & & $\mathrm{MF}+\mathrm{UtA}-\mathrm{PI}$ & $13.2(10.2-16.2)$ & 26.6 \\
\hline & & $\mathrm{MF}+\mathrm{EFW}+\mathrm{UtA}-\mathrm{PI}$ & $23.7(19.9-27.5)$ & 30.4 \\
\hline \multirow[t]{4}{*}{ Antepartum stillbirths } & 441 & $\mathrm{MF}$ & $6.4(4.1-8.7)$ & 12.9 \\
\hline & & $\mathrm{MF}+\mathrm{EFW}$ & $19.7(16.0-23.4)$ & 24.0 \\
\hline & & $\mathrm{MF}+\mathrm{UtA}-\mathrm{PI}$ & $13.8(10.6-17.0)$ & 27.7 \\
\hline & & $\mathrm{MF}+\mathrm{EFW}+\mathrm{UtA}-\mathrm{PI}$ & $24.9(20.9-28.9)$ & 32.0 \\
\hline \multirow[t]{4}{*}{ Placental dysfunction all } & 261 & $\mathrm{MF}$ & $8.8(5.4-12.2)$ & $16.9(1 ;$ \\
\hline & & $\mathrm{MF}+\mathrm{EFW}$ & $32.2(26.5-37.9)$ & $37.6(3$ \\
\hline & & $\mathrm{MF}+\mathrm{UtA}-\mathrm{PI}$ & $21.1(16.2-26.1)$ & $40.6(3$ \\
\hline & & $\mathrm{MF}+\mathrm{EFW}+\mathrm{UtA}-\mathrm{PI}$ & $40.6(34.6-46.6)$ & $48.7(4$ \\
\hline \multirow[t]{4}{*}{ Placental dysfunction $<37$ weeks } & 213 & $\mathrm{MF}$ & $10.3(6.2-14.4)$ & $19.7(1$ \\
\hline & & $\mathrm{MF}+\mathrm{EFW}$ & $38.5(32.0-45.0)$ & $44.6\left(3^{\prime}\right.$ \\
\hline & & $\mathrm{MF}+\mathrm{UtA}-\mathrm{PI}$ & $24.9(19.1-30.7)$ & $47.9(4$ \\
\hline & & $\mathrm{MF}+\mathrm{EFW}+\mathrm{UtA}-\mathrm{PI}$ & $48.8(42.1-55.5)$ & 57.3 \\
\hline \multirow{4}{*}{ Placental dysfunction $<32$ weeks } & 161 & MF & $11.8(6.8-16.8)$ & $21.1(1$ \\
\hline & & $\mathrm{MF}+\mathrm{EFW}$ & $47.8(40.1-55.5)$ & $54.7\left(4^{\prime}\right.$ \\
\hline & & $\mathrm{MF}+\mathrm{UtA}-\mathrm{PI}$ & $29.2(22.2-36.2)$ & $50.3(4$ \\
\hline & & $\mathrm{MF}+\mathrm{EFW}+\mathrm{UtA}-\mathrm{PI}$ & $58.4(50.8-66.0)$ & 65.8 \\
\hline
\end{tabular}


Table S1. Prediction of stillbirth by the competing risks model for SGA utilizing maternal risk factors and combinations with EFW and UtA-PI for all stillbirths and the subgroups of antepartum stillbirths and those that were related to placental dysfunction.

Table S2. Variables used in the RCOG guideline and the competing risks model for prediction of SGA neonates.

\begin{tabular}{ll}
\hline RCOG guideline & Competing risks model \\
\hline Not included & Race \\
Minor risk factors $(>\mathbf{3})$ & \\
Maternal age [?] 35 years & Examined but not included in the final model \\
Conception by IVF & Included \\
Nulliparous & Parity included as a protective factor \\
Body mass index $<20 \mathrm{~kg} / \mathrm{m}^{2}$ & Weight and height included as continuous variables \\
Body mass index $25-34.9 \mathrm{~kg} / \mathrm{m}^{2}$ & \\
Smoker 1-10 cigarettes per day & Smoking status included \\
Low fruit intake pre-pregnancy & Not available \\
Previous preeclampsia & Included \\
Pregnancy interval $<6$ months & Included as continuous variable \\
Pregnancy interval [?]60 months & \\
Major risk factors $(>\mathbf{1})$ & \\
Maternal age $>40$ years & Examined but not included in the final model \\
Smoker [?] 11 cigarettes per day & Smoking status included \\
Body mass index [?]35 kg/m ${ }^{2}$ & Weight and height included as continuous variables \\
Paternal SGA & Not available \\
Maternal SGA & Not available \\
Previous SGA baby & Included as continuous variable \\
Serum PAPP-A $<0.4 \mathrm{MoM}$ & Not available \\
Cocaine use & Not available \\
Daily vigorous exercise & Not available \\
Previous stillbirth & Included \\
Chronic hypertension & Included \\
Diabetes with vascular disease & Any type of diabetes \\
Renal impairment & Not included in the model \\
Antiphospholipid syndrome & Included as SLE and/or antiphospholipid syndrome \\
Heavy bleeding & Not available \\
Biophysical markers & UtA-PI included as continuous likelihood \\
UtA-PI $>95^{\text {th }}$ percentile & EFW included as continuous likelihood \\
Not included & MAP included as continuous likelihood \\
Not included & \\
\hline
\end{tabular}

PAPP-A, Pregnancy associated plasma protein-a; UtA-PI, Uterine artery pulsatility index at 20 - 24 weeks; EFW, Estimated fetal weight at $20-24$ weeks; MAP, Mean arterial pressure at $20-24$ weeks.

\section{Hosted file}

Stillbirth three models.pptx available at https://authorea.com/users/332817/articles/543238predictive-performance-for-placental-dysfunction-related-stillbirth-of-the-competingrisks-model-for-small-for-gestational-age-fetuses 